\title{
Young children are more willing to accept group decisions in which they have had a voice
}

\author{
Patricia Grocke $^{\mathrm{a}, *}$, Federico Rossano ${ }^{\mathrm{b}}$, Michael Tomasello ${ }^{\mathrm{a}, \mathrm{c}}$ \\ ${ }^{a}$ Department of Developmental and Comparative Psychology, Max Planck Institute for Evolutionary Anthropology, 04103 \\ Leipzig, Germany \\ ${ }^{\mathrm{b}}$ Department of Cognitive Science, University of California, San Diego, La Jolla, CA 92093, USA \\ ${ }^{\mathrm{c}}$ Department of Psychology and Neuroscience, Duke University, Durham, NC 27708, USA
}

\section{A R T I C L E I N F O}

\section{Article history:}

Received 12 September 2016

Revised 7 June 2017

\section{Keywords:}

Fairness

Development

Participation

Procedural justice

Voice effect

Equality

\begin{abstract}
A B S T R A C T
People accept an unequal distribution of resources if they judge that the decision-making process was fair. In this study, 3- and 5 -year-old children played an allocation game with two puppets. The puppets decided against a fair distribution in all conditions, but they allowed children to have various degrees of participation in the decision-making process. Children of both ages protested less when they were first asked to agree with the puppets' decision compared with when there was no agreement. When ignored, the younger children protested less than the older children-perhaps because they did not expect to have a say in the process-whereas they protested more when they were given an opportunity to voice their opinion-perhaps because their stated opinion was ignored. These results suggest that during the preschool years, children begin to expect to be asked for their opinion in a decision, and they accept disadvantageous decisions if they feel that they have had a voice in the decision-making process.
\end{abstract}

(c) 2017 Elsevier Inc. All rights reserved.

\section{Introduction}

Life is not always fair. We often face situations in which an authority figure makes a decision that does not favor us, and group decisions often require that we give up our advantageous position in

\footnotetext{
* Corresponding author.

E-mail address: patricia_grocke@eva.mpg.de (P. Grocke).
} 
favor of a compromise. In both cases, research has found that for adults it is easier to accept an unfavorable outcome if we have the option to state our opinion before a decision is made (Lind \& Tyler, 1988; Ong, Riyanto, \& Sheffrin, 2012). Whereas distributive justice or fairness has been quite widely investigated in both adults and children (Geraci \& Surian, 2011; Jasso, Törnblom, \& Sabbagh, 2016; Sloane, Baillargeon, \& Premack, 2012), the phenomenon described here concerns another component of justice that has received less attention-procedural justice. Being able to voice an opinion that is considered during a decision-making process is important because (a) voicing our opinion gives us the sense that we are influencing the decision-making process (Thibaut \& Walker, 1975) and (b) being able to voice an opinion gives us the sense that we are regarded as an equal and valuable group member (Tyler \& Lind, 1992).

Research in developmental psychology has shown that sensitivity of procedural justice emerges during childhood (Gold, Darley, Hilton, \& Zanna, 1984). Children are capable of evaluating the fairness of an interaction between another child and an authority figure as well as how fairly they are treated by their own mother-which affects their overall satisfaction with her (Fry \& Corfield, 1983). Hicks and Lawrence (1993) found that adolescents' concept of justice was comparable to that of adults through a study relying on a procedural justice scale based on a questionnaire about a hypothetical court situation. Among other features of fair treatment, getting a say in the decision-making process and getting an explanation as to why the final decision was made were rated as very important. In an interview study by Killen and Smetana (1999), 5-year-old children reported that they thought they should retain control over personal decisions both while at home and while in their kindergarten group. This suggests that sensitivity for participation in group decision making-a key aspect of procedural justicedevelops even before children reach school age.

Two more recent studies on procedural justice in children investigated children's sense for equality of opportunity and found that 5- and 6-year-olds already reject decision-making procedures favoring one individual over others but will accept unequal resource distributions once an impartial procedure is deployed (Grocke, Rossano, \& Tomasello, 2015; Shaw \& Olson, 2014). The latter is particularly surprising because it is known that 3-year-olds already react negatively to distributions that are unfavorable to them (LoBue, Nishida, Chiong, DeLoache, \& Haidt, 2011), and from 4 years of age onward children are even willing to take a cost to avoid getting less of a distribution than a play partner does, which is interpreted as evidence for disadvantageous inequity aversion (Blake \& McAuliffe, 2011).

The aforementioned studies on procedural justice allowed children to report on everyday experiences involving using their voice in a decision-making process (Fry \& Corfield, 1983; Hicks \& Lawrence, 1993; Killen \& Smetana, 1999). However, the only experimental study directly confronting children with situations in which they could voice their opinion about a decision was conducted by Folger (1977). In that study, 10-year-old boys worked to obtain a resource that was then distributed by a "manager," a peer of the same age. The children were either allowed to communicate their preferred distribution to the manager (voice condition) or not (mute condition). In cases of unequal distribution, the children who were allowed to voice their preference were more satisfied with their outcome than the mute children. This result is in line with findings from adult research showing that procedural justice becomes important when outcome fairness is violated (Brockner \& Wiesenfeld, 1996). A second measure of Folger's (1977) study showed a preference for getting to voice an opinion-even independent of the fairness of the outcome. When asked to evaluate the fairness of the procedure (manager dividing the resource), the children rated the voice procedure as fairer than the mute procedure both when their outcome was equal to the manager's outcome and when they received less. The reported studies show that school-age children expect and appreciate having a voice in decisionmaking processes just like adults do. However, studies on distributive justice demonstrate that children prefer and expect fairness way before they start school (DesChamps, Eason, \& Sommerville, 2016; Schmidt \& Sommerville, 2011). Whether they also develop a preference for fair decisionmaking processes (procedural justice), with regard to participation within their preschool years has yet to be investigated.

Therefore, we conducted a study with 3- and 5-year-old children playing a resource allocation game with two puppets. In this game, the group needed to choose between two distributions of stickers; one was equal (each player received two stickers), whereas the other was unequal-leaving a child at a disadvantage. In all conditions, the puppets always chose the option that was unfavorable toward 
a child. However, we manipulated how the puppets treated the child during the decision-making process in a total of four conditions, each with an increasing level of participation of the child.

We measured the children's spontaneous reactions to the puppets' behavior-whether children voiced protest against or agreed with the puppets' actions. Measuring children's protest is a common practice to investigate young children's perceptions of normative transgressions (see, e.g., Kenward, 2012; Rakoczy, Warneken, \& Tomasello, 2008; Rossano, Rakoczy, \& Tomasello, 2011). If children perceive the situation in an instrumental way (participate to control individual outcome) or a moral way (participate because it is morally wrong to be excluded in a decision-making process), they should protest most when being ignored, and their protest should decrease as they increasingly are asked to participate in the decision-making process.

During the experimental manipulation, children could also feel that they were being socially excluded. If this were the case, they should show more affiliative behavior when being ignored than in the other conditions. In a decision-making process, conformity to the other group members' opinion could be interpreted as an attempt to affiliate with the group and avoid conflict. Haun and Tomasello (2011) showed that 4- and 5-year-old children adjust to their group's (erroneous) opinion when making judgments about the size of an animal even when they knew better. In our task, agreeing to the puppets' decision would mean accepting an outcome that is unfavorable toward them. Social belonging is an existential human need rather than a mere desire (Baumeister \& Leary, 1995), and so children might approve a loss of outcome in order to reestablish their inclusion in the group. The two behavioral measures-spontaneous protest and agreement-define the two poles of possible behaviors in group decision making: asserting oneself in spite of possible future negative reactions from the group and accepting an unfavorable group decision in order not to jeopardize group membership.

To conclude the experiment, we conducted an interview after the test asking the children to judge the fairness of the puppets' behavior and whether they would want to play with the puppets again. We predicted that unfair play partners would be avoided in favor of fairer play partners (Baumard, André, \& Sperber, 2013).

\section{Method}

\section{Participants}

We tested 160 participants ( 80 girls and 80 boys) from two age groups ( $M=5$ years 6 months, $S D=$ 1 month and $M=3$ years 6 months, $S D=1$ month) in a between-participants design with 20 children (10 girls and 10 boys) in each condition and age group. The sample size was specified prior to data collection, based on typical sample sizes in this field. The children came from mixed socioeconomic backgrounds and were recruited via urban day-care centers (in which testing took place). We visited 20 different day-care centers. All of the children who had informed consent from their parents and matched the relevant age range were included in the sample. An additional 13 children were tested but excluded because of experimenter error $(n=4)$, the child did not show a preference for two stickers over one sticker $(n=4)$, the child refused more than twice to agree with the puppets in the agreement condition $(n=3)$, or the child did not follow the procedure $(n=2)$. All participating children gave verbal consent to participate and had the informed consent of their parents.

\section{Material and procedure}

Testing was conducted by an experimenter and an assistant. The experimenter picked each child up from his or her kindergarten group, explained the game, left the room during the test phase, and then interviewed the child after the test. The assistant played the two puppets during the test phase. She was not introduced as a person-but rather as the pig and the cow-and never left these roles in the presence of the child.

Each child went through the four phases of the experiment. First, the child and the puppets played a warm-up game (see online supplemental material) to get to know each other and to train the child to expect that the puppets were fallible rather than authority figures. This is the current method used for 
studies looking at children's protesting behavior; it shows children that they are allowed to intervene in the social interaction with the puppets (see, e.g., Rossano et al., 2011). Then the test apparatus was brought in, and the experimenter explained what the apparatus was to the child (see supplemental material). This was followed by two test trials. For the test, the experimenter introduced a wooden box called a "treasure chest" (see Fig. 1). The box was divided into an upper side and a lower side. Both sides were filled with three small paper boxes that contained stickers and were the same color of the cushions on which the puppets and the child were sitting. Each side was covered by a transparent lid. Both lids were blocked by a bar in the middle, which needed to be moved to the upper side to open the lower lid or to the lower side to open the upper lid. Once the bar was moved, it snapped into place and could not be moved anymore. At the end of the experiment, the child was interviewed and debriefed by the experimenter.

\section{Test}

For the test, the distribution of the stickers in the treasure chest was as follows: an equal side with two stickers in each box and an unequal side with three stickers for the pig (puppet with advantage), two stickers for the cow (neutral puppet), and only one sticker for the child. It would have been advantageous for the pig if they chose the unequal side, neither side was advantageous for the cow, and it would have been advantageous for the child if they chose the equal side. The roles of the puppets changed in the second trial.

The experimenter presented the stickers in the treasure chest and asked the participants one after the other (pig, cow, and child) to remember their colors and count the stickers inside the two boxes.
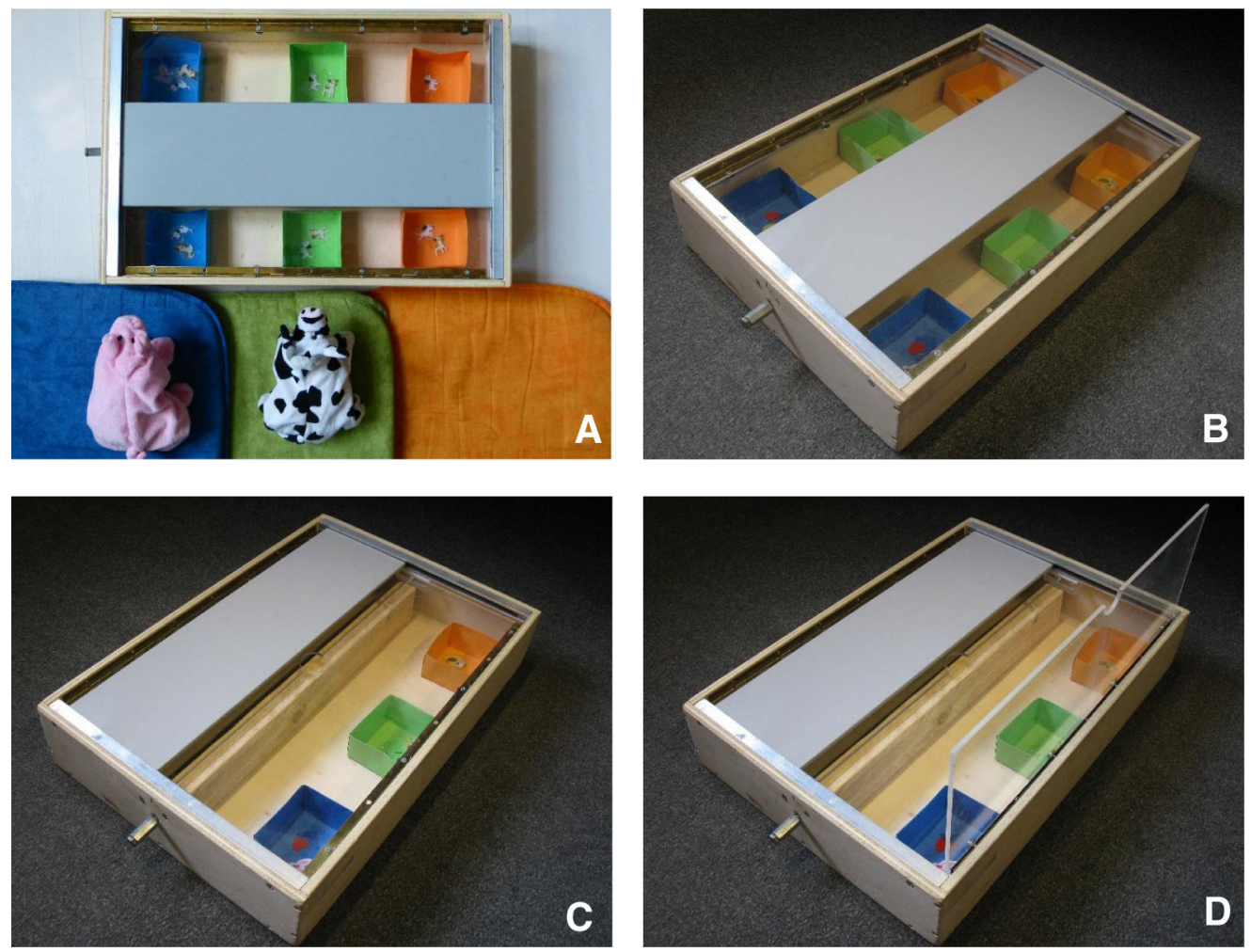

Fig. 1. (A) Setup of the test apparatus ("treasure chest") with puppets sitting on blue and green cushions and an orange cushion for the child. (B and C) Mechanism for decision and opening. The gray bar in the middle between the two options could be moved up or down depending on the decision. (D) This uncovered one of the two transparent lids, which could then be opened. The bar could no longer be moved back. 
However, the experimenter did not ask which side they preferred. The experimenter then encouraged the group members to play on their own, reminded them to choose one side to open, and then left the room. When the experimenter was gone, the pig looked at the treasure chest and stated its choice aloud. Then the cow looked at the treasure chest and stated its choice aloud. In all conditions, both puppets chose the side with the unequal distribution of stickers. Next, the puppets started moving the gray bar slowly. When the bar reached the final position, the puppets stepped back but kept looking at the boxes and waited for the child's reaction. After a few seconds, they opened the treasure chest, took their sticker boxes out, and counted their stickers aloud.

The behavior of the puppets toward the child differed according to the conditions (see Table 1 for an overview). In the no voice condition, the puppets just stated their choice one after another (e.g., "I want the top/bottom side!"). In the voice condition, the puppets asked the child for his or her opinion ("[Child's name], tell me, which side do you want to take?") and then stated their own choice. In the voice + justification condition, the puppets asked the child for his or her opinion, stated their own choice, and gave a justification for their choice being different from the child's choice one after the other (e.g., "I want to take the top side because it's my birthday today"). The puppet with the advantage (with the opportunity to get three stickers) always stated that today was its birthday. The neutral puppet (which would receive two stickers in any case) stated that it wanted to take the same side that the birthday puppet had just chosen (e.g., "I want to take the top side because it's the cow's birthday today"). In the second trial, the former neutral puppet had the option to get three stickers and justified its choice by saying that "it was my birthday yesterday." In the voice + justification + agreement condition, the puppets asked the child for his or her opinion, stated their own choice, gave a justification for that choice one after the other, and then asked the child to agree with their choice (e.g., "I want to take the top side because it's my birthday today. Can we do that, please?"). Each child played two trials in the test phase. The sticker distribution of the second trial was changed so that the cow had three stickers on the unequal side and the pig had two. When the child did not agree, the puppets asked a second time. If the child still did not agree, the puppets proceeded with the procedure (either the second puppet stated its choice and asked for agreement or the two puppets moved the bar). Children who refused to agree with the puppets more than two times were excluded from the sample.

\section{Interviews}

After the test, the experimenter used a third puppet-a cat-to ask the interview questions. She sent the other puppets out of the room to make sure that the child was not influenced by the presence of his or her former play partners.

The following is a sample transcript of the interview:

"[Child's name], I want to ask you a secret question. But first the cow and the pig have to leave the room. Otherwise, it wouldn't be secret anymore."

"Was it okay or was it unfair (okay or unfair*) how the pig and the cow played with you?"

"Why was it okay/unfair*?"

"Would you play with the pig and the cow again, or would you rather play with someone else (with someone else or again with the pig and the cow*)?"

"Why would you play again with them/rather play with someone else*?"

*We counter-balanced the order in which the two possible answers were used in the question (unfair/okay and again with the pig and the cow/with someone else).

Table 1

Manipulation of participation in puppets' behavior toward the child.

\begin{tabular}{llll}
\hline Condition & Features of puppets' behavior \\
\hline No voice & Ignore child & & \\
Voice & Ask for opinion & & \\
Voice + justification & Ask for opinion & Justify differing opinion & Ask for agreement \\
Voice + justification + agreement & Ask for opinion & Justify differing opinion & Ask \\
\hline
\end{tabular}


After the interview, the experimenter (as the cat) debriefed the child by saying that the game was not fair and allowed the child to pick three more stickers out of another box.

\section{Measurement and coding}

All sessions were videotaped and coded by the first author. One quarter (25\%) of the video recordings were coded a second time for reliability by a research assistant who was blind to the research hypothesis $(\kappa=.901$ for the coded behavior, $\kappa=1$ for the answers to Question 1 of the interview, and $\kappa=.934$ for the answers to Question 2 of the interview).

In the warm-up, the child watched the puppets unsuccessfully attempt to play a game in four different situations. We coded after how many cues the child intervened (0-3) or whether the child did not intervene at all (4). The scores were used as an ordinal measure of shyness $(0=$ not shy at all, $4=$ very shy). This was used to check for possible age differences in children's general tendency to protest. ${ }^{1}$

In the main test, we coded whether the child voiced a protest against the puppets' actions or accepted their choice as a binary measure. Coding began after the second puppet had stated its choice and the two puppets started to move the bar, in turn blocking the lids. Coding ended when the child took his or her sticker box out of the treasure chest.

In the pilot study, which was conducted before data collection for the current study started, we observed different ways in which children showed their disapproval of the puppets' actions, which led to the development of our coding scheme categories for protest. Verbal protest included any utterance from a child that was aimed at stopping the puppets from moving the bar. This could have been a single "No!" or a complete sentence such as "You didn't ask me!" or "I want the other side." Behavioral protest included any action by a child that was aimed at stopping the puppets from moving the bar or the rejection of the sticker box that was assigned to the child as a result of the puppets' choice (blocking). This could mean blocking the bar when the puppets were moving it, or trying to move it, in the other direction. If a child did not take his or her sticker box out after the puppets had moved the bar and tried to move it back to get the other boxes, this was also coded as behavioral protest (rejection). Both of these behaviors needed to occur together to be counted as a clear rejection of the puppets' choice. A child who did not take out his or her box, but was not trying to get the other box, might simply have been too shy to take it. If a child took out the box and then tried to get the other one, the child might have just been trying to take as much as he or she could get. Verbal and behavioral protests were collapsed for the analysis.

As a measure of conformity, we coded whether the child spontaneously changed his or her mind and agreed with the puppets' decision for the no voice, voice, and voice + justification conditions. In the voice + justification + agreement condition, the child was asked to agree with the puppets. Thus, this condition was excluded with regard to that specific measure.

The dichotomous questions asked in the interview were answered in a binary way by the children and coded as such.

\section{Results}

The experiment provided a measure of protest against the puppets' actions, a measure of spontaneous conformity with the puppets' choice, and an interview measure from the answers to the interview questions. They were analyzed regarding the effect of participation in the decision-making procedure on children's acceptance of the inequality of the reward distribution in two dimensions (expression of disapproval and attempts to reestablish the threatened social bond) and the judgment of the procedure. Significant effects are reported in the following sections. Additional analyses of the children's verbal judgment of the procedure can be found in the supplemental material.

\footnotetext{
${ }^{1}$ In total, 32 3-year-olds and 29 -year-olds intervened in all four trials without receiving any cue by the experimenter operating the puppets or the experimenter. Except for 13 -year-old girl, all children corrected the puppets at least one time during the warm-up. We ran a generalized linear model to test whether there were any differences in protesting behavior between the two age groups ( 3 -year-olds: $M=1.825$; 5 -year-olds: $M=1.671$ ) and controlled for gender. Age had no effect on how many cues the children received before they corrected the puppets' behavior $(Z=0.414, p=.68)$.
} 
Protest against the puppets' actions

The first dependent variable was whether the child had protested against the puppets' actions. We tested the influence of age group and degree of participation on children's protest and controlled for gender effects (see Fig. 2). We ran a generalized linear mixed model (Baayen, 2008) in which we included age group (3-year-olds or 5-year-olds), condition (no voice, voice, voice + justification, or voice + justification + agreement), and gender as fixed effects. Furthermore, we included the interaction of age group and condition. Overall, the full model was significant (likelihood ratio test: $\chi^{2}=$ $50.321, d f=7, p<.001$ ) in comparison with a null model (comprising only gender). There was no effect of gender $(Z=1.083, p=.298)$. We found a significant interaction between age group and condition (likelihood ratio test comparing a model including the interaction of age groups and condition with another model including no interaction: $\chi^{2}=14.324, d f=3, p=.002$ ). We specifically looked at the differences between contiguous conditions by multiple comparisons of factor contrasts (no voice/ voice, voice/voice + justification, and voice + justification/voice + justification + agreement $)$ using the package phia (De Rosario-Martinez, 2015) within the program R (R Core Team, 2016).

The 3-year-olds protested less when they were ignored (no voice) compared with when they were able to voice their opinions (voice) $(Z=3.606, p<.001)$. In the three voice conditions (voice, voice + justification, and voice + justification + agreement), a decrease of protest with increasing participation was observed; the 3-year-olds protested most in the voice condition (vs. the voice + justification condition: $Z=-2.286, p=.022$ ) and least in the voice + justification + agreement condition (vs. the voice + justification condition: $Z=-2.061, p=.039$ ).

The 5 -year-olds did not show a difference of protest between the no voice condition and the voice condition $(Z=-0.229, p=.819)$. In the three voice conditions (voice, voice + justification, and voice + justification + agreement), no difference was observed between the voice and voice + justification conditions $(Z=-0.242, p=.808)$. However, they protested significantly less in the voice + justification + agreement condition than in the voice + justification condition $(Z=-1.961, p=.050)$.

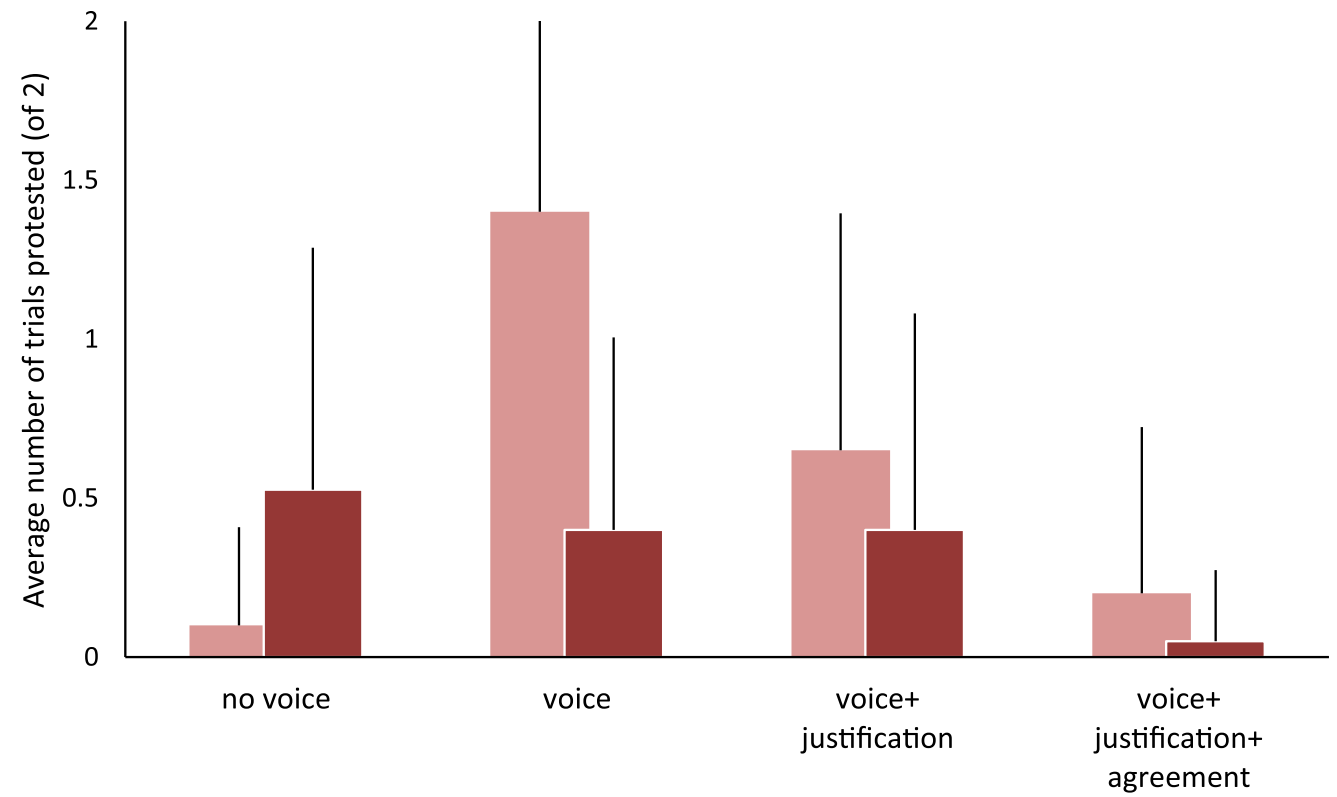

3-year-olds 5-year-olds

Fig. 2. Mean protest (two trials) and standard deviation for the no voice condition (ignoring the child) and the three degrees of participation of the child in the decision-making process: voice, voice + justification, and voice + justification + agreement. 
We also found differences of protest frequency between 5- and 3-year-olds in some conditions. When they were ignored (no voice), the older children protested more than the younger children $(Z$ $=2.078, p=.038$ ). When they were given the opportunity to voice their opinions (voice), however, the older children protested less than the younger children $(Z=-2.962, p=.003)$. In the other two conditions, there was no age effect (voice + justification: $Z=-1.080, p=.280$; voice + justification + agreement: $Z=-1.240, p=.215$ ).

\section{Forms of verbal and behavioral protest}

When children protested verbally against the puppets' actions, we observed four different kinds of utterances. Most children (70\%) repeated or emphasized their personal choice (e.g., "But I wanted that side!"). The second most common kind of utterance (20\%) highlighted the consequences of the puppets' behavior for children's own outcome (e.g., "But then I'll only get one sticker!"). Two more types of utterances were comparatively rare and used only by 5 -year-olds, with $7 \%$ of the children specifically protesting against the decision-making process (e.g., "You didn't ask me!") and 3\% of the children showing moral protest (e.g., "That's unfair! You just want to get more than me").

When children showed behavioral protest against the puppets' actions, we observed two different kinds of behaviors. Children blocked the gray bar when the puppets started moving it in $55 \%$ of the cases. Children rejected the unfavorable sticker box when the treasure chest was opened in $45 \%$ of the cases. The 5-year-olds predominantly blocked the gray bar when the puppets tried to move it, whereas the 3-year-olds predominantly rejected the sticker box after the treasure chest was opened.

\section{Conformity measure}

In the no voice, voice, and voice + justification conditions, another possible reaction toward the puppets' behavior was spontaneous agreement. This does not seem to reflect disapproval of the puppets' behavior because of instrumental or moral considerations (like the protest measure); rather, it appears to be a reaction to the feeling of being socially excluded. We tested the influence of age group and degree of participation on children's spontaneous agreement with the puppets' decision and controlled for gender effects. We ran a generalized linear mixed model (Baayen, 2008) in which we included age group (3-year-olds or 5-year-olds), condition (no voice, voice, or voice + justification), and gender as fixed effects. Furthermore, we included the interaction of age group and condition. Overall, the full model was significant (likelihood ratio test: $\chi^{2}=22.863, d f=5, p<.001$ ) in comparison with a null model (comprising only gender). We found no significant interaction between age group and condition (likelihood ratio test comparing a model including the interaction of age groups and condition with another model including no interaction: $\chi^{2}=5.117, d f=2, p=.077$ ). There was no effect on gender $(Z=0, p=1)$ and no effect on age $(Z=0.785, p=.376)$. Concerning condition effects, we found that the children showed more spontaneous agreement when they were ignored (no voice condition) than when they were asked for their opinion (voice condition) $(Z=3.225, p=.001$ ). There was no difference between the voice and voice + justification conditions $(Z=0.242, p=.808)$.

\section{Interview measure}

Following the test, children were interviewed by the experimenter using a cat puppet. They were asked whether the behavior of the other puppets was unfair or okay (Question 1) and whether they would play with the two puppets again or would rather play with someone else (Question 2). Answers to both questions were coded dichotomously (see Table 2 for results). We ran a generalized linear mixed model (Baayen, 2008) for each question, in which we included age group (3-year-olds or 5year-olds), condition (no voice, voice, voice + justification, or voice + justification + agreement), and the interaction of these two factors. We controlled for gender and the structure of the question (order of answer options). Because our independent variables, age group and condition, had no effect on the children's answers on the interview questions, we refrained from analyzing the data further (see supplemental material for detailed statistical analysis and additional graphs). 
Table 2

Proportions of children (out of 20 per cell) answering Question 1 ("Was it unfair or okay how the puppets played?") with "okay" and proportions of children answering Question 2 ("Would you play again with the cow and the pig?") with "yes".

\begin{tabular}{|c|c|c|c|c|c|}
\hline \multicolumn{3}{|l|}{ Question 1} & \multicolumn{3}{|l|}{ Question 2} \\
\hline Condition & $\begin{array}{l}\text { 3-year-olds } \\
(\%)\end{array}$ & $\begin{array}{l}\text { 5-year-olds } \\
(\%)\end{array}$ & Condition & $\begin{array}{l}\text { 3-year-olds } \\
(\%)\end{array}$ & $\begin{array}{l}5 \text {-year-olds } \\
(\%)\end{array}$ \\
\hline No voice & 75 & 75 & No voice & 45 & 50 \\
\hline Voice & 75 & 75 & Voice & 40 & 25 \\
\hline Voice + justification & 85 & 85 & Voice + justification & 60 & 30 \\
\hline $\begin{array}{l}\text { Voice + justification } \\
+ \text { agreement }\end{array}$ & 75 & 65 & $\begin{array}{l}\text { Voice + justification } \\
+ \text { agreement }\end{array}$ & 40 & 40 \\
\hline
\end{tabular}

\section{Discussion}

We used a novel procedure to investigate preschoolers' protesting behavior as a function of involvement in decision-making procedures. In this study, each child interacted with two puppets making a decision that was unfavorable toward the child and allowed him or her differing degrees of participation in the decision-making process.

The two age groups differed with regard to their protesting behavior. The 3-year-old children showed the opposite pattern of what was found in studies with adults and adolescents (Bies \& Shapiro, 1988; Folger, 1977; Folger, Rosenfield, Grove, \& Corkran, 1979); that is, they were not bothered about being ignored in the decision-making process. However, they frequently protested when they were allowed to voice their opinion before the decision. The 5-year-old children showed no difference in their levels of protest when they were asked for their opinion as opposed to when they were ignored. However, they protested more than the younger children when they were ignored but less when they were allowed to voice their opinion. Young children are used to having adults decide for them. The older they get, the more they experience being given a choice and being able to influence their social world at home as well as in their kindergarten group (Killen \& Smetana, 1999; Nucci \& Weber, 1995). At 3 years of age, the children in our study might just not have expected to be given a voice, which might explain why they did not protest when ignored. At 5 years of age, however, the children were no longer indifferent about being ignored. They demonstrated an expectation about being treated equally and being included in a decision-making process that affected them, which is in line with observations that Killen and Smetana (1999) made in kindergartens. This was also reflected in the kind of protest the children in our study produced. Some of the older children explicitly protested against being ignored and complained about unfairness. The 3-year-olds, however, only asserted their choices or complained about the consequences that the puppets' choice had on their own outcome. Whereas young children expect their expressed desires to have an effect, older children have already learned that they cannot always get their way. This might be the first step toward an appreciation of participation in a decision-making process that is detached from the outcome produced by it. The reason for this developmental change might be that between 3 and 5 years of age, inhibitory control and other executive functions begin to develop (Best \& Miller, 2010; Wiebe et al., 2011). Being able to inhibit their first disapproval of getting fewer stickers than desired might have made it easier for the older children to decide not to protest against the unfavorable outcome and, thus, to behave in a more socially adaptive way instead.

Besides protest, we further observed a contrary kind of reaction to the puppets' behavior. When ignored and not asked to voice their opinion, children of both age groups spontaneously agreed with the puppets' choice (conformed). However, they did not do so when they were allowed to voice their opinion before the decision was made. Being excluded when a group makes a decision is not only unfair in a procedural way-it also constitutes a form of ostracism that threatens our social need to belong (Over, 2016; Williams, 1997, 2002). When they were ignored, the children in our study readily changed their mind and agreed to the puppets' choice even though conforming meant that they would get a smaller distribution of a resource (only one sticker instead of two stickers). Some children even imitated the way the puppets stated their choice in wording and pronunciation. Imitation is a behavior 
that is typically used to reestablish group membership after experiencing ostracism (Over \& Carpenter, 2009; Watson-Jones, Legare, Whitehouse, \& Clegg, 2014). But the children in our study did not do so when they were allowed to voice their opinion before the puppets made their choice. This shows that when social belonging is endangered, the need to reestablish social bonds can trump the desire to get the most favorable outcome. On the continuum between making compromises in favor of the group and asserting oneself, conforming to the majority's opinion is the most defensive strategy. However, from an instrumental perspective, it would be sensible to protest against unfair treatment by other group members because individuals need to defend themselves from exploitation by others. Such a protest can be justified by the moral principle that no one should be disadvantaged if at all possible, which might cause the group to accept the objection instead of excluding the protesting individual from the group. When a group makes a decision about resource allocation, therefore, every affected member should have the possibility to voice his or her opinion. Whereas children of both age groups showed the same pattern of affiliative behavior toward the puppets, they differed with regard to their protesting behavior. Children of both age groups reacted to the social experience of being excluded by adopting the group's opinion. In addition to this rather defensive strategy, only 5-yearolds protested against being excluded in the decision-making process. Their motivation might have been instrumental (if they aimed at getting a better outcome) or moral (if they begin to understand that they should be asked for their opinion and that being excluded is morally wrong).

Besides allowing all affected parties to voice their opinion, a further feature of a fair decisionmaking procedure is giving a justification. A justification of an unfavorable outcome can influence people's fairness judgments positively because it allows people to determine whether the decision maker was biased toward his or her own interests (Bies \& Shapiro, 1987, 1988). In our study, the puppets' justification decreased the 3-year-olds' tendency to protest, but it did not do so for the 5-year-olds. It might have changed the younger children's expectations about their payoff by giving a reasonable explanation as to why the group should behave in favor of another group member. For the older children, however, not expecting their wish to be complied with given an explanation might have been redundant. Alternatively, the given justification might just not have been convincing enough for the older children. However, future work could investigate children's reaction to justifications that might be more or less acceptable (e.g., "One of my previous stickers was torn" vs. "Because it is raining").

Being asked to agree with the puppets' choice was the condition with the highest degree of participation and respect toward the children and had the same effect on both age groups; namely, it lowered the tendency to protest. This is in line with the hypothesis assuming that the quality of the social interaction (procedural justice) affects how even young children perceive a decision-making process. In the framework of our study, the puppets' respectful behavior toward the children might have trumped the children's disappointment about having an unfavorable outcome. Indeed, we observed children who happily agreed and promptly began to carry out the agreed-on action. However, others only reluctantly agreed with the puppets (but still did not protest against their action). So, alternatively, it is possible that the given agreement had a strong committing effect on the children, and they no longer felt entitled to protest (Gräfenhain, Behne, Carpenter, \& Tomasello, 2009; Hamann, Warneken, \& Tomasello, 2012). Further research is needed to investigate the motivation for the specific behavior children demonstrated in this condition.

Studies with adults show some limitations to the voice effect; people do not react positively to being given an opportunity to voice their opinion if they did not expect it (Bos, Vermunt, \& Wilke, 1996) or if they feel a high-power difference between themselves and the decision maker (Brockner et al., 2001). Both might have been the case in our study, especially if the children were influenced by the presence of the adult experimenter holding the puppets, which we cannot rule out. During early childhood, social interactions are often regulated by adults who decide what is right and wrong and what children are supposed to do. However, it is highly unlikely that differences in the protest of the two age groups result from 3-year-olds being shyer or less likely to speak up for themselves given that we found no difference in their protesting behavior during the warm-up.

At kindergarten age, children start to interact with peers as equals (Howes, Rubin, Ross, \& French, 1988). In such interactions, children make key developmental steps toward having their own understanding of morality and fairness (Piaget, 1965). For future research, therefore, it would be interesting to investigate participation in group decisions in peer contexts instead of using puppets. Such a setup 
would also be more suitable to test children older than our participants and investigate how the voice effect develops throughout the early school years. Another way to look at children's expectations and fairness concerns would be to put them in the position of the decision maker in order to see whether they themselves would include play partners in the process or decide alone.

We created a study design to investigate preschoolers' reactions to different degrees of participation in a decision-making process. Between 3 and 5 years of age, children's willingness to accept unfavorable outcomes after being asked for their opinion increases. At the same time, their willingness to accept being ignored in a decision-making process decreases. These are important steps toward becoming members of society who can assert themselves as well as make compromises in favor of the group.

\section{Appendix A. Supplementary material}

Supplementary data associated with this article can be found, in the online version, at http://dx.doi. org/10.1016/j.jecp.2017.08.003.

\section{References}

Baayen, R. H. (2008). Analyzing linguistic data: A practical introduction to statistics using R. New York: Cambridge University Press. Baumard, N., André, J. B., \& Sperber, D. (2013). A mutualistic approach to morality: The evolution of fairness by partner choice. Behavioral and Brain Sciences, 36, 59-78.

Baumeister, R. F., \& Leary, M. R. (1995). The need to belong: Desire for interpersonal attachments as a fundamental human motivation. Psychological Bulletin, 117, 497-529.

Best, J. R., \& Miller, P. H. (2010). A developmental perspective on executive function. Child Development, 81, 1641-1660.

Bies, R. J., \& Shapiro, D. L. (1987). Interactional fairness judgments: The influence of causal accounts. Social Justice Research, 1 , 199-218.

Bies, R. J., \& Shapiro, D. L. (1988). Voice and justification: Their influence on procedural fairness judgments. Academy of Management Journal, 31, 676-685.

Blake, P. R., \& McAuliffe, K. (2011). "I had so much it didn’t seem fair”: Eight-year-olds reject two forms of inequity. Cognition, $120,215-224$.

Bos, K., Vermunt, R., \& Wilke, H. A. (1996). The consistency rule and the voice effect: The influence of expectations on procedural fairness judgements and performance. European Journal of Social Psychology, 26, 411-428.

Brockner, J., Ackerman, G., Greenberg, J., Gelfand, M. J., Francesco, A. M., Chen, Z. X., ... Shapiro, D. (2001). Culture and procedural justice: The influence of power distance on reactions to voice. Journal of Experimental Social Psychology, 37, $300-315$.

Brockner, J., \& Wiesenfeld, B. M. (1996). An integrative framework for explaining reactions to decisions: Interactive effects of outcomes and procedures. Psychological Bulletin, 120, 189-208.

De Rosario-Martinez, H. (2015). Phia: Post-Hoc Interaction Analysis. <https://CRAN.R-project.org/package=phia>.

DesChamps, T. D., Eason, A. E., \& Sommerville, J. A. (2016). Infants associate praise and admonishment with fair and unfair individuals. Infancy, 4, 478-504.

Folger, R. (1977). Distributive and procedural justice: Combined impact of voice and improvement on experienced inequity. Journal of Personality and Social Psychology, 35, 108-119.

Folger, R., Rosenfield, D., Grove, J., \& Corkran, L. (1979). Effects of "voice" and peer opinions on responses to inequity. Journal of Personality and Social Psychology, 37, 2253-2261.

Fry, P. S., \& Corfield, V. K. (1983). Children's judgments of authority figures with respect to outcome and procedural fairness. Journal of Genetic Psychology, 143, 241-250.

Geraci, A., \& Surian, L. (2011). The developmental roots of fairness: Infants' reactions to equal and unequal distributions of resources. Developmental Science, 14, 1012-1020.

Gold, L. J., Darley, J. M., Hilton, J. L., \& Zanna, M. P. (1984). Children's perceptions of procedural justice. Child Development, 55, 1752-1759.

Gräfenhain, M., Behne, T., Carpenter, M., \& Tomasello, M. (2009). Young children's understanding of joint commitments. Developmental Psychology, 45, 1430-1443.

Grocke, P., Rossano, F., \& Tomasello, M. (2015). Procedural justice in children: Preschoolers accept unequal resource distributions if the procedure provides equal opportunities. Journal of Experimental Child Psychology, 140, 197-210.

Hamann, K., Warneken, F., \& Tomasello, M. (2012). Children's developing commitments to joint goals. Child Development, 83, 137-145.

Haun, D., \& Tomasello, M. (2011). Conformity to peer pressure in preschool children. Child Development, 82, $1759-1767$.

Hicks, A. J., \& Lawrence, J. A. (1993). Children's criteria for procedural justice: Developing a young people’s procedural justice scale. Social Justice Research, 6, 163-182.

Howes, C., Rubin, K., Ross, H., \& French, D. (1988). Peer interaction of young children. Monographs of the Society for Research in Child Development, 53(1, Serial No. 217).

Jasso, G., Törnblom, K. Y., \& Sabbagh, C. (2016). Distributive justice. In C. Sabbagh \& M. Schmitt (Eds.), Handbook of social justice theory and research (pp. 201-218). New York: Springer.

Kenward, B. (2012). Over-imitating preschoolers believe unnecessary actions are normative and enforce their performance by a third party. Journal of Experimental Child Psychology, 112, 195-207. 
Killen, M., \& Smetana, J. G. (1999). Social interactions in preschool classrooms and the development of young children's conceptions of the personal. Child Development, 70, 486-501.

Lind, E. A., \& Tyler, T. R. (1988). The social psychology of procedural justice. New York: Springer Science \& Business Media.

LoBue, V., Nishida, T., Chiong, C., DeLoache, J. S., \& Haidt, J. (2011). When getting something good is bad: Even three-year-olds react to inequality. Social Development, 20, 154-170.

Nucci, L., \& Weber, E. K. (1995). Social interactions in the home and the development of young children's conceptions of the personal. Child Development, 66, 1438-1452.

Ong, Q., Riyanto, Y. E., \& Sheffrin, S. M. (2012). How does voice matter? Evidence from the ultimatum game. Experimental Economics, 15, 604-621.

Over, H. (2016). The origins of belonging: Social motivation in infants and young children. Philosophical Transactions of the Royal Society B: Biological Sciences, 371, 20150072.

Over, H., \& Carpenter, M. (2009). Priming third-party ostracism increases affiliative imitation in children. Developmental Science, 12, F1-F8.

Piaget, J. (1965). The moral judgment of the child. New York: Free Press. (Original work published 1932).

R Core Team (2016). R: A language and environment for statistical computing. Vienna, Austria: R Foundation for Statistical Computing. <https://www.R-project.org/>.

Rakoczy, H., Warneken, F., \& Tomasello, M. (2008). The sources of normativity: Young children's awareness of the normative structure of games. Developmental Psychology, 44, 875-881.

Rossano, F., Rakoczy, H., \& Tomasello, M. (2011). Young children's understanding of violations of property rights. Cognition, 121, 219-227.

Schmidt, M. F., \& Sommerville, J. A. (2011). Fairness expectations and altruistic sharing in 15-month-old human infants. PLoS ONE, 6(10), e23223.

Shaw, A., \& Olson, K. (2014). Fairness as partiality aversion: The development of procedural justice. Journal of Experimental Child Psychology, 119, 40-53.

Sloane, S., Baillargeon, R., \& Premack, D. (2012). Do infants have a sense of fairness? Psychological Science, 23, $196-204$.

Thibaut, J. W., \& Walker, L. (1975). Procedural justice: A psychological analysis. Hillsdale, NJ: Lawrence Erlbaum.

Tyler, T. R., \& Lind, E. A. (1992). A relational model of authority in groups. Advances in Experimental Social Psychology, 25, $115-192$.

Watson-Jones, R. E., Legare, C. H., Whitehouse, H., \& Clegg, J. M. (2014). Task-specific effects of ostracism on imitative fidelity in early childhood. Evolution and Human Behavior, 35, 204-210.

Wiebe, S. A., Sheffield, T., Nelson, J. M., Clark, C. A., Chevalier, N., \& Espy, K. A. (2011). The structure of executive function in 3year-olds. Journal of Experimental Child Psychology, 108, 436-452.

Williams, K. D. (2002). Ostracism: The power of silence. New York: Guilford.

Williams, K. D. (1997). Social ostracism. In R. M. Kowalski (Ed.), Aversive interpersonal behaviors (pp. 133-170). New York: Springer. 